RASĀYAN J. Chem.

Vol. 13 | No. 2 |1187-1192| April - June | 2020 ISSN: 0974-1496 | e-ISSN: 0976-0083 | CODEN: RJCABP http://www.rasayanjournal.com http://www.rasayanjournal.co.in

\title{
RISK ASSESSMENT, SCREENING AND CONTROLS OF ELEMENTAL IMPURITIES IN PHARMACEUTICAL DRUG PRODUCTS: A REVIEW
}

\author{
R. K. Chawla*, S. Panda, K. Umasankar, S. P. Panda and D. Damayanthi \\ K. L. College of Pharmacy, Koneru Lakshmaiah Education Foundation, Vaddeswaram, \\ Guntur, Andhra Pradesh, India 522502 \\ *E-mail: rbchawla07@gmail.com
}

\begin{abstract}
The scope of this article is to review and describe the steps involved in risk assessment of elemental impurities (EIs) in drug products based on the permitted daily exposure (PDE) limits for the twenty-four (24) elements that are considered as potential EIs. Screening and estimation of EIs in drug substances, excipients and drug products by Inductively Coupled Plasma Mass Spectrometry (ICP-MS) or Inductively Coupled Plasma Optical Emission Spectrometry (ICP-OES) and their controls involved as referred in the general chapters $<232>\&<233>$ of the United States Pharmacopoeia (USP), Q3D guideline for Elemental Impurities as per International Conference on Harmonization (ICH) and Q3D Elemental Impurities: guidance for Industry as per U. S., Food and Drug Administration US-FDA (US-FDA).
\end{abstract}

Keywords: Risk Assessment, Elemental Impurities (EIs), Screening, Control.

(C) RASĀYAN. All rights reserved

\section{INTRODUCTION}

EIs in pharmaceutical drug products have no therapeutic effect and may be harmful hence should be brought down to the safety levels if any. EIs in drug products could be contributed either from drug substances, excipients as natural, artificial colors, flavoring agents, manufacturing processes, manufacturing equipment, instruments, water, solvents, containers, closures, and many other sources. These EIs from various sources combined together can be potentially hazardous to human health. ${ }^{1-4}$

To control these impurities, the non-selective visual limit test specified under USP General Chapter $<231>^{5}$ is being replaced by the specific, selective and quantitative instrumental technique following USP General Chapters $<232>\&<233>^{6-7}$ and ICH Q3D guideline. ${ }^{8}$ In USP General Chapter $<232>$ (Elemental Impurity Limits) \& $<233>$ (Elemental Impurity Procedures) concentration limits are set for fifteen (15) elements in pharmaceutical drug products and two procedures are established for determination by ICPMS (Inductively Coupled Plasma - Mass Spectrometry) and ICP-OES (Inductively Coupled PlasmaOptical Emission Spectrometry). ${ }^{6-7}$ Whereas under ICH-Q3D guideline, permitted for daily exposure of twenty-four (24) elements. EIs testing are now becoming mandatory from January 2018 for new approvals and existing approvals ${ }^{9}$.

\section{Risk Assessment of Elemental Impurities in Drug Product}

The ICH Q3D guideline established the threshold values for 24 different elements based on toxicological data for various exposure paths. These EIs are classified according to the permitted daily exposure (PDE) and the possibility of occurrence in the drug products, into three classes (Table-1). ${ }^{10-12}$

Class-1: These elements are toxic for humans and have limited or not permitted to use in the manufacture of pharmaceuticals $(\mathrm{Hg}, \mathrm{Pb}$, As and $\mathrm{Cd})$.

Class-2: These elements are toxic for humans depending on the route of administration and further divided into sub-classes $2 \mathrm{a}$ and $2 \mathrm{~b}$ depending on their relative possibility of presence in the drug product.

Rasayan J. Chem., 13(2), 1187-1192(2020)

http://dx.doi.org/10.31788/RJC.2020.1325079

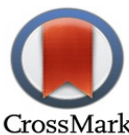


RASĀYAN J. Chem.

Vol. 13 | No. 2 |1187-1192| April - June | 2020

Class-2A: These elements are considered for risk assessment due to their high probability of presence in the drug product $(\mathrm{Co}, \mathrm{Ni}$ and $\mathrm{V})$.

Class-2B: These elements have less possibility of presence in the drug product due to their low abundance and the low possibility to be co-isolated with the other materials (Os, $\mathrm{Ag}, \mathrm{Ir}, \mathrm{Au}, \mathrm{Pd}, \mathrm{Pt}, \mathrm{Ru}$, $\mathrm{Rh}, \mathrm{Tl}$ and $\mathrm{Se})$.

Class-3: These elements are less toxic for humans by the oral route of administration unless these elements are intentionally added (Ba, $\mathrm{Cr}, \mathrm{Sn}, \mathrm{Li}, \mathrm{Mo}, \mathrm{Sb}$ and $\mathrm{Cu})$.

Except for these EIs, if any other EIs are present or included in the drug product they have to be addressed. Some of these elements considered as sodium (Na), tungsten (W), and zinc ( $\mathrm{Zn}$ ), aluminium $(\mathrm{Al})$, boron $(\mathrm{B})$, calcium $(\mathrm{Ca})$, iron $(\mathrm{Fe})$, potassium $(\mathrm{K})$, magnesium $(\mathrm{Mg})$, manganese $(\mathrm{Mn}) .{ }^{10,13}$

EIs specifications and EIs screening results from vendor/supplier of each component of drug products (drug substances, inactive excipients, container closure systems, and manufacturing equipment/instruments etc.) are used for maximum daily exposure (MDE) calculation purposes. MDEs are compared with ICH Q3D guideline for EIs with their PDEs to demonstrate compliance. ${ }^{14-17}$

MDE of each elemental impurity (EI) is determined by two methods: ${ }^{10,18}$

(i) Based on vendor/supplier statements and

(ii) Individual component EI screening results.

The calculated MDE of each individual EI is compared with the PDE limits for the EI as established in ICH Q3D to check the compliance for the particular route of administration. The final approach should be developed to ensure the EIs do not exceed the PDE, based on the outcome of risk assessment results. ${ }^{19-20}$ In method (i) MDE for each EI in a formulation is calculated as follows using the available vendor/supplier statements as follows:

1. Calculate each ingredient's quantity (per unit dose) to obtain total daily intake (TDI) in grams (g) for that ingredient based on MDD (maximum daily dose) of the drug product.

2. Multiply the weight (grams) of each component of TDI with the EI's specification $(\mu \mathrm{g} / \mathrm{g})$ value (maximum specification value is taken for calculation) from the vendor's certificate of analysis/statement. This gives the $\mu \mathrm{g}$ per day of the EI for that ingredient.

3. To determine the MDI (total $\mu \mathrm{g}$ ) of each EI per day sum the individual quantities ( $\mu \mathrm{g} /$ day) obtained for each component of the drug product in Step-2.

4. Repeat the above MDI calculation for each EI of concern and compare it with the EI permissible daily exposure established in ICH Q3D.

The method (ii) MDI for each EI in a formulation is calculated as follows using the analytical data generated:

1. Convert each product EI level in $\mu \mathrm{g} / \mathrm{g}$ to total daily intake in $\mu \mathrm{g}$ as MDI. Multiply the EI $(\mu \mathrm{g} / \mathrm{g})$ value with the weight of the product (in g per day) to get the maximum daily intake ( $\mu \mathrm{g}$ per day) of the EI for the product.

2. Repeat the above MDI calculation for each EI of concern and compare it with the EI PDE established in ICH Q3D.

If EIs listed in Table-1 are added intentionally as a catalyst/inorganic reagent in drug substances or excipients or co-isolated from manufacturing equipment and process or from container closure systems, then these elements should be considered in the risk assessment of drug product. ${ }^{10,21-22}$ The elements Cobalt (Co), Thallium (Tl), Gold (Au), Selenium (Se), Silver (Ag), Lithium (Li), Antimony (Sb), Barium (Ba), Tin (Sn) are not considered in USP general chapter $<232>^{6}$.

If the risk assessment process does not identify any potential EI then it is considered that the potential EI assessment process is concluded.

The summary of risk assessment should consider the importance of the calculated and/or predicted levels of the EI relative to the PDE of the EI. For the observed significant EI level, a control threshold of 30 
RASĀYAN J. Chem.

Vol. 13 | No. 2 |1187-1192| April - June | 2020

percent of the established PDE in the drug product should be defined. If the total EIs level in the drug product is predicted to be always less than 30 percent of the PDE, then, in this case, maybe no further additional controls required, provided that the assessment is done properly and demonstrated adequate controls on EI. In case the risk assessment fails to show that an EI levels are less than the control threshold, further controls should be established which ensures that the EI level does not exceed the PDE in the drug product.

Table-1: Elements to be considered in the Risk Assessment as per ICH Q3D Guideline

\begin{tabular}{|c|c|c|c|c|c|c|c|c|}
\hline \multirow{2}{*}{$\begin{array}{c}\text { Element } \\
\text { Cadmium }(\mathrm{Cd}) \\
\end{array}$} & \multirow{2}{*}{$\begin{array}{c}\text { Class } \\
1\end{array}$} & \multirow{2}{*}{$\begin{array}{c}\text { If intentionally } \\
\text { added (All Routes)* } \\
\text { Yes }\end{array}$} & \multicolumn{2}{|c|}{$\begin{array}{l}\text { Oral, PDE } \\
\mu \mathrm{g} / \text { Day* }\end{array}$} & \multicolumn{2}{|c|}{$\begin{array}{l}\text { Parenteral, } \\
\text { PDE } \mu \mathrm{g} / \text { day* }\end{array}$} & \multicolumn{2}{|c|}{$\begin{array}{l}\text { Inhalation, } \\
\text { PDE } \mu \mathrm{g} / \text { day* }\end{array}$} \\
\hline & & & Yes & 5 & Yes & 2 & Yes & 2 \\
\hline Lead $(\mathrm{Pb})$ & 1 & Yes & Yes & 5 & Yes & 5 & Yes & 5 \\
\hline Arsenic (As) & 1 & Yes & Yes & 15 & Yes & 15 & Yes & 2 \\
\hline Mercury (Hg) & 1 & Yes & Yes & 30 & Yes & 3 & Yes & 1 \\
\hline Cobalt (Co) & $2 \mathrm{~A}$ & Yes & Yes & 50 & Yes & 5 & Yes & 3 \\
\hline Vanadium (V) & $2 \mathrm{~A}$ & Yes & Yes & 100 & Yes & 10 & Yes & 1 \\
\hline Nickel (Ni) & $2 \mathrm{~A}$ & Yes & Yes & 200 & Yes & 20 & Yes & 5 \\
\hline Thallium (Tl) & $2 \mathrm{~B}$ & Yes & No & 8 & No & 8 & No & 8 \\
\hline Gold $(\mathrm{Au})$ & $2 \mathrm{~B}$ & Yes & No & 100 & No & 100 & No & 1 \\
\hline Palladium (Pd) & $2 \mathrm{~B}$ & Yes & No & 100 & No & 10 & No & 1 \\
\hline Iridium (Ir) & $2 \mathrm{~B}$ & Yes & No & 100 & No & 10 & No & 1 \\
\hline Osmium (Os) & $2 \mathrm{~B}$ & Yes & No & 100 & No & 10 & No & 1 \\
\hline Rhodium (Rh) & $2 \mathrm{~B}$ & Yes & No & 100 & No & 10 & No & 1 \\
\hline Ruthenium $(\mathrm{Ru})$ & $2 \mathrm{~B}$ & Yes & No & 100 & No & 10 & No & 1 \\
\hline Selenium (Se) & $2 \mathrm{~B}$ & Yes & No & 150 & No & 80 & No & 130 \\
\hline Silver (Ag) & $2 \mathrm{~B}$ & Yes & No & 150 & No & 10 & No & 7 \\
\hline Platinum (Pt) & $2 \mathrm{~B}$ & Yes & No & 100 & No & 10 & No & 1 \\
\hline Lithium (Li) & 3 & Yes & No & 550 & Yes & 250 & Yes & 25 \\
\hline Antimony (Sb) & 3 & Yes & No & 1200 & Yes & 90 & Yes & 20 \\
\hline Barium $(\mathrm{Ba})$ & 3 & Yes & No & 1400 & No & 700 & Yes & 300 \\
\hline Molybdenum (Mo) & 3 & Yes & No & 3000 & No & 1500 & Yes & 10 \\
\hline Copper $(\mathrm{Cu})$ & 3 & Yes & No & 3000 & Yes & 300 & Yes & 30 \\
\hline $\operatorname{Tin}(\mathrm{Sn})$ & 3 & Yes & No & 6000 & No & 600 & Yes & 60 \\
\hline Chromium $(\mathrm{Cr})$ & 3 & Yes & No & 11000 & No & 1100 & Yes & 3 \\
\hline
\end{tabular}

*If elements added intentionally, then those elements should be considered for risk assessment or the elements indicated in Table-1 should be considered based on the route of administration. $\mu \mathrm{g} /$ day $=$ microgram per day .

The PDE of each of EI that may be contained in the maximum daily intake of a drug product is reported in micrograms per day $(\mu \mathrm{g} /$ day). The options are established which describe approaches to establish the level of EI in pharmaceutical drug products or its components that would assure that the drug product does not exceed the PDEs. ${ }^{10-11,23}$

Option-1: When the daily intake of the drug product is not more than 10 grams.

Option-2a: Common permitted concentration limits across drug product components for a drug product with a specified daily intake.

Option-2b: Permitted concentration limits of elements in individual components of a product with a specified daily intake. 
RASĀYAN J. Chem.

Vol. 13 | No. 2 |1187-1192| April - June | 2020

Option-3: Finished product analysis.

\section{Screening of Elemental Impurities, Analytical Procedures and Validation}

The EIs should be determined using suitable procedures for the intended purposes. The procedure should be specific for each EI identified for control during the risk assessment. Pharmacopoeial procedures or any other suitable procedures should be used for determining levels of EI. ${ }^{24-26}$

USP general chapter $<233>^{7}$ prescribed two instrumental procedures (Procedures 1 and 2) for the determination of the EI and acceptance criteria for any alternative procedures or approaches that meet the validation requirements. ${ }^{27}$

Procedure-1 can be used for determination of EI by ICP-OES (Inductively Coupled Plasma-Optical Emission Spectrometry) and Procedure-2 by ICP-MS (Inductively Coupled Plasma-Mass Spectrometry). For both, the procedures sample preparations should be optimized based on the sample nature and recoveries of the EI. Generally, sample preparation can be done by direct dissolving in aqueous or organic solutions, when a material is soluble. If the test material is not soluble in aqueous and organic solvents or mixture, an indirect solution can be obtained by digesting the sample using the "Closed vessel digestion" procedure with a suitable concentrated acid. ${ }^{28-30}$

Based on the number of elements to be determined in the drug product, single or multiple methods the sample preparations can be adopted to get the desired signal intensity for the target elements and acceptable recoveries of elements. ${ }^{31-32}$

If the prescribed USP procedures do not meet the specific application, an alternative procedure may be adopted and must be validated following the validation requirements for alternative procedures ${ }^{33}$. Validation parameters like accuracy, precision, specificity, linearity, the limit of quantification, range and solution stability ${ }^{34}$ should be demonstrated as per the acceptance criteria specified in USP general chapter $<233>$.

\section{Controls}

Control of EI in drug product is to assure that EI does not exceed the PDEs. When the EI in risk assessment and screening (analysis) in the drug product shows the level is 30 percent or less of the established PDE in the drug product then no further controls are required and acceptable, if the process, drug substances and excipients vendors are not to be changed in future. When the EI in risk assessment and screening (analysis) in the drug product shows the level is more than 30 percent and less than the established PDE in the drug product then further controls are required and testing may be applied to EI according to the principles described in ICH Q6A, which should be a part of specification. ${ }^{35-38}$

When the level of EI exceeds the established PDEs (control threshold), additional measures should be implemented to assure that the level does not exceed the PDE. The following approaches can be used to control the EI level ${ }^{39-41}$ by:

- Selection of drug substance and excipients vendors, who periodically monitors and controls the levels of EI and establishment of specification for drug substance and excipients.

- Selection of manufacturing equipment, container closure systems, water source which meets the compendia requirements and following the Good Manufacturing Practice (GMP).

- Understanding, modification of the steps in the manufacturing process and implementation of inprocess controls that result in the reduction of EI below the control threshold in the drug product.

\section{CONCLUSION}

Risk assessment of EI in drug products is a must as it gives necessary information about the presence of each individual EI which helps in the selection of process, make and grade of excipients, manufacturing equipment and container and closure systems. The information of EI is also required to keep necessary controls through screening which is a regulatory requirement and a part of drug product filling.

ACKNOWLEDGMENT

The authors are thankful to Suven Life Sciences Limited, Hyderabad for their support and encouragement in writing this review article. 
RASĀYAN J. Chem.

Vol. 13 | No. 2 |1187-1192| April - June | 2020

\section{REFERENCES}

1. A. Teasdale, C.C. Chery, G. Cook, Pharmaceutical Technology, 39(3), 8(2015).

2. Elemental Impurities: A Virtual Company Perspective, Contract Pharmaceuticals(2017).

3. R. Santamaria-Fernandez, S. Merson and R. Hearn, Semiquantitative Screening of Pharmaceutical Antiviral Drugs using the Agilent 7500ce ICP-MS in Helium Collision Mode, Application Note, Queens Road, Teddington, Middlesex, (2016).

4. Implementation of ICH Q3D Elemental Impurities Guideline: Challenges and Opportunities, Pharmaceutical Technology, 39(3), (2015).

5. The United States Pharmacopoeia 40, The National Formulary 35, General Chapter $<231>$ - Heavy Metals, United States Pharmacopeia Convention, (2017).

6. The United States Pharmacopoeia 40, The National Formulary 35, General Chapter <232> Elemental Impurities - Limits, United States Pharmacopeia Convention, (2017).

7. The United States Pharmacopoeia 40, The National Formulary 35, General Chapter <233> Elemental Impurities - Procedures, United States Pharmacopeia Convention, (2017).

8. International Conference on Harmonisation, Q3D - Guideline for Elemental Impurities, Step-4 Version, International Conference on Harmonization, IFPMA, Geneva, (2014).

9. Elemental Impurities in Drug Products - Guidance for Industry, U.S. Department of Health and Human Services, Food and Drug Administration, (2018).

10. Q3D Elemental Impurities - Guidance for Industry, U.S. Department of Health and Human Services, Food and Drug Administration, (2018).

11. Implementation Strategy of ICH Q3D Guideline, Committee for Medicinal Products for Human use, European Medical Agency, (2017).

12. Product Risk Assessment General Approach, Q3D Training Module 5, International Council for Harmonisation of Technical Requirements for Pharmaceuticals for Human Use, (2016).

13. M.G. Schweitzer, Implementation of ICH Q3D, FDA/PQRI Conference on Evolving Product Quality, (2014), Retrieved from http://pqri.org/wp-content/uploads/2015/11/Schweitzer.pdf

14. Container Closure Systems for Packaging Human Drugs and Biologics - Guidance for Industry, U.S. Department of Health and Human Services, Food and Drug Administration, (1999).

15. G. Li, D. Schoneker, K.L. Ulman, J.J. Sturrn, L.M. Thackery and J.F. Kauffman, Journal of Pharmaceutical Sciences, 104(12), 4197(2015), DOI:10.1002/jps.24650

16. D. Jenke, C. Rivera, T. Mortensen, P. Amin, M. Chacko, T. Tran and J. Chum, PDA Journal of Pharmaceutical Science and Technology, 69, 1(2015), DOI:10.5731/pdajpst.2015.01005

17. D. Jenke, C. Stults, D. Paskiet, D. Ball and L. Nagao, PDA Journal of Pharmaceutical Science and Technology, 69(1), 1(2015).

18. ICP-MS and ICP-OES to Measure Trace Elemental Impurities in Pharmaceuticals in Compliance with Proposed Pharmacopeia Chapters, By Spectroscopy Editors, Spectroscopy, 26(3), (2011).

19. A. Teasdale, C.C. Chéry, G. Cook, J. Glennon, C. W. Lee, L. Harris, N. Lewen, S. Powell, H. Rockstroh, L. Rutter, L. Smallshaw, S. Thompson, V. Woodward and K. Ulman, Pharmaceutical Technology, 39(3), (2015).

20. Calculation Options, Q3D training module 7, International Council for Harmonisation of Technical Requirements for Pharmaceuticals for Human Use, (2016).

21. Brazilian Pharmacopeia - 5th Ed., Chapter 5.3.2.3 Limit test for heavy metals, the assay method. National Sanitary Surveillance Agency - ANVISA, (2010).

22. N. Lewen, S. Mathew, M. Schenkenberger and T. Raglione, Journal of Pharmaceutical and Biomedical Analysis, 35(4), 739(2004), DOI:10.1016/j.jpba.2004.02.023

23. J. Prajapati, Journal of Generic Medicines, 13(3), 123(2017), DOI:10.1177/1741134317699244

24. R.N. Rao, M.V.N.K. Talluri, Journal of Pharmaceutical and Biomedical Analysis, 43(1), 1(2007), DOI: $10.1016 / j . j p b a .2006 .07 .004$

25. M. Rury, Spectroscopy, 31(5), 16(2016).

26. S.R. Kallam, J. Srikanth and K.V. Prakash, IOSR Journal of Pharmacy and Biological Sciences, 11(4), 6(2016), DOI:10.9790/3008-1104020611 
RASĀYAN J. Chem.

Vol. 13 | No. 2 |1187-1192| April - June | 2020

27. C. Stoving, H. Jensen, B. Gammelgaard and S. Sturup, Journal of Pharmaceutical and Biomedical Analysis, 84, 209(2013), DOI:10.1016/j.jpba.2013.06.007

28. J. Sims, A. Smith, D. Patel, R. Batchelor and J. Carreira, Journal of Laboratory Automation, 16(5), 377(2011), DOI:10.1016/j.jala.2010.10.006

29. C. Venzago, M. Popp, J. Kovac and A. Kunkel, Journal of Analytical Atomic Spectrometry, 28(7), 1125(2013), DOI:10.1039/C3JA50040C

30. H. Matusiewicz, Physical Sciences Reviews, 2(5), (2017), DOI:10.1515/psr-2017-8001

31. B.O. Axelsson, M.J. Karlsson, P. Michelsen, F. Abou-Shakra, Rapid Communications in Mass Spectrometry, 15(6), 375(2001), DOI: 10.1016/S0301-4770(04)80033-2

32. A.L.H. Muller, E.I. Muller, J.S. Barin, E.M.M. Flores, Analytical Methods, 7(12), 5218(2015), DOI: $10.1039 / \mathrm{C} 5 \mathrm{AY} 00436 \mathrm{E}$

33. J.S. Barin, P.A. Mello, M.F. Mesko, F.A. Duarte and E.M.M. Flores, Analytical and Bioanalytical Chemistry, 408 (17) , 4547(2016), DOI: 10.1007/s00216-016-9471-6

34. International Conference on Harmonization, Q2(R1) - Validation of Analytical Procedure: Text and Methodology, Step-4 Consensus Guideline, International Conference on Harmonization, IFPMA, Geneva, (1994).

35. Controls of Elemental Impurities, Q3D training module 6, International Council for Harmonisation of Technical Requirements for Pharmaceuticals for Human Use, (2016).

36. FDA Perspective and Expectations for Control of Elemental Impurities in Drug Products, PQRI/USP Workshop on Implementation Status of ICH Q3D, Rockville, MD, (2016), Retrieved from http://pqri.org/wp-content/uploads/2016/11/4-EI-FDAperspectivedPQRI.pdf.

37. E.F. Brandon, A.G. Oomen, C.J. Rompelberg, C.H. Versantvoort, J.G. van Engelen and A.J. Sips, Regulatory Toxicology and Pharmacology, 44(2), 161(2006), DOI:10.1016/j.yrtph.2005.10.002

38. International Conference on Harmonisation, Q6A - Specifications: Test procedures and acceptance criteria for new drug substances and drug products, Step-4 version, International Conference on Harmonization, IFPMA, Geneva, (1999).

39. U. Wollein, B. Bauer, R. Habernegg and N. Schramek, European Journal of Pharmaceutical Sciences, 77, 100(2015), DOI:10.1016/j.ejps.2015.05.028

40. A.J. DeStefano, K. Zaidi, T.L. Cecil, G.I. Giancaspro, and the USP Elemental Impurities Advisory Panel, Elemental Impurities-Information, Pharmacopeial Forum, 36(1), (2010).

41. R.C. Rowe, P.J. Sheskey and M.E. Quinn, Handbook of Pharmaceutical Excipients, Sixth edition. Pharmaceutical Press, London, (2009).

[RJC-5079/2019] 